\title{
On the Innovative Elements of Cowboy Clothing
}

\author{
Nan Qiao \\ College of textile and garment, Hebei University of Science and Technology, China \\ 519910777@qq.com
}

\begin{abstract}
Keywords: Cowboy clothing; Innovation elements; Fabric; Fashion unrest; Vitality
\end{abstract}
\begin{abstract}
Through the analysis of the development process of cowboy clothing, the paper studies the innovation perspective and characteristics of cowboy clothing. A comprehensive, in-depth, stereoscopic analysis and combing of the main innovative elements of cowboy clothing are carried out, especially the fabric. The paper systematically expounds the design performance of the innovative elements of cowboy clothing, and explores the diversity characteristics of fashion trend of cowboy clothing. Pointing out the richness of finding the design language continuously and combine with the humanistic culture and artistic creation, this will make the vitality of cowboy clothing be continuously extended and improved.
\end{abstract}

\section{Introduction}

There is Without doubt that denim clothing belong to young people. Although many "Old-fashioned" have always been interested in denim clothing, they still belong to the "Youth subculture" in the eyes of scholars. In recent years, as people's ideas become more open and diverse, cowboy clothing has become a unique style of consumer choice. At the same time, in the past two years, that many popular elements and details of fashion trends, "cowboy unrest" swept the fashion world again, driving and leading the trend of the direction. Gucci, Burberry Prorsum, Jean Paul Gaultier, Dolce \& Gabbana and other major brands have used denim elements, "cowboy" with its uninhibited, casual wear and avant-garde feel very popular.

\section{The Cultural Connotation of Cowboy Clothing}

The Criginal Characteristics of Cowboy Costume. Denim clothing is one of the most popular clothing besides the suitIts innate charm. It's unique aesthetic features and growing opportunities for the times, make it a popular product of the new century, and gradually developed into a worldwide cowboy culture ${ }^{[1]}$. The jeans as a representative, it is the original gold tooling, the appearance of rough, wearing body, reflects the natural beauty of the human body, the fabric is usually stone blue or navy blue denim, by people of all ages are, in modern life. In the process of accepting the denim, love the denim, they feel sexy and rough, aesthetic and innovative, wanton and unassuming.

As far as the cowboy clothing is concerned, its characteristics are becoming less and less, and the Western Cowboy's appearance is becoming more and more diluted. Various fashion elements are added to the denim design, from tradition to classics to fashion, clothing and leisure wear. In the innovation of technique in addition to the usual washing across the material, use, destruction, washing special fringed dyeing, fabric reconstruction and other techniques ${ }^{[2]}$.The denim, which was originally used on the frock, has become a symbol of the designers' minds and has a different texture after the baptism of the times.

The Evolution of Denim Costume. As early as 16 and seventeenth Century Europe, jeans are used to refer to denim, it original is gold overalls, after Levy Strauss officially adopted was popular in the United states. Back in the 1950s, jeans were a constant element in jeans costume. In twentieth Century, 70 and 80s, the punk rock wind created another craze for jeans. Some famous designers designed different styles of denim clothing, which became the most fashionable dress at that time. So far, many fashion elements have joined them, whether they are the original pattern of scattered 
and recombine, or in style, color, material, technology, finishing and other aspects of the exploration and innovative design ${ }^{[3]}$.

Since 90s, when cowboy clothing became popular, designers dealt with the functions, materials and decorations of denim clothing more diverse.

The Social Value of Denim Clothing. Denim clothing are a very practical dress. Denim clothing is comfortable and durable and requires no special maintenance. Its functionality and comfort are the prevailing premises. China has become an important producer of denim in the world, and a large number of more advanced denim and denim clothing have reached international standards in quality and variety. Denim clothing sales steady growth, and enduring. These are enough to explain the great potential of the denim clothing market.

Now designers are also trying to cowboy style diversification, the cowboy and high fashion, high-end clothing, fashion dress and so on to together, to subvert the image of the cowboy, allowing consumers to see the cowboy amorous feelings.

\section{The Use of Innovative Elements in Denim Costumes}

With the development of denim clothing, it's innovative elements have been excavated and become the highlight of the design. Innovative elements are developed and extended in style, color, decoration, and especially material, which make denim clothing break out from the original traditional cowboy concept.

Style Detail Design. Stick to the traditional line in cowboy clothing style design details in hand, have retained the traditional characteristics from cutting characteristics, washing method to clothing and accessories; on the other hand, according to the popular changes continue to get new inspiration, detrusion the innovative style and leading the trend. Cowboy fashion trend is more sophisticated and attention to detail, through new cutting, new dyeing method, washing process and personalized design, such as draping, personality process, sense of hierarchy processing, geometric segmentation, make the cowboy clothing showing a trend of diversification, urbanization is more and more strong.

Reinventing denim Proportion. One can see that traditional Cowboys make new tailoring ratios by zooming in and out. If make the traditional women's dress, Knight vest and plaid shirt shoulder position sink, pocket bigger; and men's vest is overall elongated; shirt big pocket is located in the shirt and jacket in the middle, increasing the sense of hierarchy. The Construction ism profile of Japanese designer Kenzo in spring and summer, 2015, adopts the improvement of super size jeans and coat profile, so that people can see the extraordinary charm of constructionism.

New style denim clothing. In pace with the denim and the denim blended to appearance , and the rise of light smooth soft fabric denim fabric, by creating wrinkles at the waist to control loose jeans, and by adding size on leisure trouser to emphasis the staste of arder ${ }^{[4]}$.At the same time, these fabrics are also used in the shirt, dress, dress and all kinds of pants on.

Plurality of Colors. In terms of color, with the rich material and texture of denim fabric and the development of dyeing process, besides the traditional indigo, it has been developed to use different tone of blue and make them to blend with other colors.2017 spring and summer denim fabric trends in color, from the deepest blue chrysanthemum, dark bule navy blue and metallic blue to cold, the amplitude of the blue is dominant. Yellow, red, and orange are become excellent decorations color; brown, forest green and traditional Khaki tones have also returned to men's and women's clothing.

Innovative Interpretation of Material and Fabric Technology. The so-called fabric innovation in cowboy dress, that is in the original basis will comply with the aesthetic principles of fabric combined with modern technology, through the deconstruction and reorganization, reconstruction methods, change the fabric appearance and characteristics of the original, in order to achieve the purpose of rich and innovative fabrics.

Unique Techniques of Denim Clothing. In the 2016 and 2017 year fashion trends, washing denim presents a new and more rich pattern effect trend, and exaggeration and distinct of contrast is the key. Dose - enhanced wash arrange and interesting various surface textures form striking pattern effects. Mainly performance is brown stains and black and white treatment, in the flower pattern has become more abstract, and clever use of rhythm, proportion and contrast design. 
Some well-known international cowboy brands also display their unique positioning through their unique. Such as: Nostalgia classic Levi 's, simple random Cavin Klein, their cowboy products use enzyme washing and sand washing; the sexy of Miss Sixty and independence of Diesel is use of a large number of severe wash and damage wash to reflect their own unique. In the popular trend of denim fabric in 2017 also appeared on the back of the interval dyeing, designers are in the understanding of the brand positioning, grasp the differences of their products, so as to choose the processing method suitable for the brand.

Nowadays Post Finishing and Post Processing. In the use of cowboy washing process, the raw materials after a variety of finishing and post-processing, has become a means of material processing. Such as hand pleated, crimp, a drape and brushed denim processing, stone washing technology is sand washing, porcelain ball washing technology is replaced, the coating also adds a lot of fashion elements for denim. In the surface of the fabric to reflect the effect of glazing or luster, the use of digital laser engraving on cowboy fabric printing or float cutting, but also formed a visual graphics innovation.

The widespread use of high technology combines the characteristic process with modern art, and forms a new design language characterized by visual innovation and process flexibility. It has become a new way of thinking for the development of denim clothing.

Re Creation of Denim. The re creation of denim clothing materials is mainly the creation and change of cowboy fabric and other fabric in the material, texture and decoration. Cotton denim fabric with blended, there will be a run or waxy stiff feeling; thin silk denim fabric, soft, thin and moisture, have cool and elegant feeling in visual and wearing; weaving coarse hemp polyester denim fabric will produce strong fortitude effects such as ${ }^{[5]}$.At the same time, different treatments such as tying, folding, twisting, stacking, wrinkling and filling will also produce a wide variety of denim fabrics. In the re-creation of use such as dyeing, weaving, embroidery, painting, carving, corrosion, filling, sprayed gold (silver) and other techniques, will also increase the fabric texture to rich. In the spring and summer of 2016, several Chanel denim clothing were made with monochrome jacquard technology, which made the clothing have a "dream" printing effect.

In the process of re-creation of fabric, it can also be combined with fabric in accordance with different styles of clothing to re-creation. Such as the elegant style denim can choose lace, ribbon decoration; sports and leisure style can add some wool, linen fabrics, knitted fabrics, moldings, zippers and other; avant-courier style through the old, torn, corrosion, holes and other means, or rivets, coating, plastic, metal, glass, light emitting material; luxury style is available making satin, velvet, beads, embroidery on fabric decoration for processing ${ }^{[6]}$. Alexander McQueen2016 and launched a cowboy is denim fabric with diamond jewelry show, luxury, exquisite effect; those who had only used in high fashion, in combination with traditional handicraft and high-tech fabric re-design technique, also appeared in the jeans, Marc Jacobs is making the cowboy clothing and cloth, embroidery the combination of clothing production, colorful and lively punk sense.

New Jeans Fabric. With the advent of new fibers, some high-performance special fibers have also been adopted by denim fabrics. Such as: Coolnice-Lycra (a Cool denim fabric) is a moisture absorption, humidity and moisture wicking effect is very good fabrics, and has a cool feeling. This fabric is particularly suitable for sports and leisure wear, and it has good elasticity, extensibility, retention, stability and heat setting properties, the fabric can be flexible and lightweight breathable, comfortable and durable and easy dyeing; there is a Richcel and Cotton Blended Elastic Thin denim fabric with alkali a strong fabric finishing, good adaptability and stability. This fabric has some characteristic, such as bright and clean, smooth, hygroscopic and sweat releasing, soft ;and it's delicate and silky, drape, stiff and smooth;. Another one is Espol-Stretch yarn denim fabric, its unique high elasticity and tightness, make more fitted clothing products, increase cowboy clothing movement flexibility, suitable for people to sports and leisure ${ }^{[7]}$.At the same time, the fabric has excellent softness and elasticity, crease resistance, dimensional stability, weathering resistance, easy to dye, is very good, made clothing wearing comfortable, soft touch, easy washing, drying, ironing, people with the fast pace of life requirements. 


\section{Trend of Cowboy Clothing}

In the wheel of fashion, cowboy trends have been taking hold in recent years. Both the 2015 "self-cultivation Cowboy", 2016 "loose jeans"; many innovative design of fabric fashion trends in 2017; or "pure color and fine tailoring" cowboy, "elegant Cowboy" and "Luxury cowboy" label, both in shape and color especially material etc., showing the most incisive creative the expression of.

The Collage, Tear Storm. The modern designer's "collage and tear" is often used in denim jeans. In addition to a collage of different denim colors, the wool, velvet, corduroy, and tannins are combined with denim to give a gorgeous retro silhouette. In 1960s the hippie style inspiration, multi-layer spliced forms of different colors and different kinds of fabric collocation, bringing people to another kingdom cowboy story, using the edge after special treatment denim clothing shaping the future generations of the evening banquet ${ }^{[8]}$.In 2017, Christopher Bailey will denim and leather tassels bright, stitching, become a new understanding and interpretation of the cowboy trend; and the most commonly used technique is the tear in the denim apparel make a hole, make your drooping naturally, show the Bohemian rough ${ }^{[9]}$.

The Washing and Dyeing Storm. Denim have many washing patterns in 2016, and dark rough wash once again become a hot spot, while black denim washing has become a striking trend, the different warm gray is also one of the highlights, and appeared both restore ancient ways of light or dark wash water denim, at the same time, dirty old and fading effect also reflects the old antique effect. Lee, Wrangler, IBS and other professional denim brands, while the different levels of the blue color on the canvas, resulting in yellow, green or blue brush blasting effect.

The Take out the Thread and Printing Storm. Denim is the blue and white cotton line weft woven cloth, the surface is blue, but because take out the thread from denim, make under the white cotton lines were exposed, presenting with rolling white selvedge, it's very dazzling. The spring and summer denim of 2016 in Anna Sui by a group "LOOK star" pattern in her garment design printing, showing a consistent style of magic; and 3D printing technology has also been optimistic about the experts considered to replace the digital printing of the fashion design and the new favorites; Chloé sets of cowboy fabric made mill white and flash, reflecting the classic, nostalgic feeling with ${ }^{[10]}$.In 2017, the trend of denim fabrics was more distinctive: such as mesh and denim stitching, embossed sense of jacquard, back interval dyeing, float cutting, denim, edge wear, and so on, have become new highlights.

\section{Peroration}

Through the research, the author believes that the innovative elements of cowboy clothing can be created around the various ideas and angles of the cowboy costume itself. The development of innovative elements has brought vitality to primitive cowboy clothing, enriched its connotation and denotation, and even made the clothing of different categories draw a strong cowboy wind.

In the field of cowboy clothing, "innovation" can be reflected in the clothing of the local and global two processing, processing of shape, color and material damage, retro, printing and dyeing, stains and so on; can also reflect different other prominent new denim clothing modelling, such as deconstruction, elegant and mix of denim clothing; can also be expressed as decoration and embellishment of clothing with a variety of techniques, and different combinations of existing elements, collocation, form of exaggeration, deconstruction and so on .

Of course, as a cowboy clothing designer, but also in the mining of its innovative elements at the same time, pay attention to the combination of regional culture and fashion style, new aesthetic, new style and new image, in the simple physical creation, increase the overall clothing culture, fashionable and artistic, will make the jeans vitality continue to improve. 


\section{Reference}

[1] Liu Xiaogang .Special clothing design [M]. second edition. Shanghai: Donghua University press, 2013, 76

[2] Xuwei.For discussion of modern jeans, [J]. international textile Herald, 2016; 10:10-12

[3] Zhang Minguang. Crazy jeans, [M]., Jilin science and Technology Press, 2015.11

[4] Chen Xinming. Development trend of cowboy clothing [J]. Journal of Zhongyuan University of Technology, 2014; 15-16.

[5] Zhang Xiaowei. The application and artistic expression of fabric redesign in jeans. Textile weekly, 2015, 6-2

[6] Wang Qinping. On fashion cowboy culture [J]. modern art and design, 2013, 8.

[7] Wang Shuang. New denim fabrics. Hebei textile, 2009, 1-65

[8] Jia Juan, Wang Jihui. Discussion on the reasons for the popularity of jeans. Chemical fiber and textile technology, [J].2005, 1-37

[9] Gong Weiwei. Cowboy fashion style and design features [J]. silk, 2015.12

[10] Li Xianmeng. Storm storm fabric, [J]. fashion, 2016.2 